\title{
SINERGIA
}

REVISTA DO INSTITUTO DE CIÊNCIAS ECONÔMICAS, ADMINISTRATIVAS E CONTÁBEIS (ICEAC)

\section{EFETIVIDADE DO USO DA COMPENSAÇÃO POR ROYALTIES DE MINERAÇÃO SOB A PERSPECTIVA DAS GERAÇÕES FUTURAS}

DAYSE MARA GONÇALVES LAVRA* FRANCISCO ANTÔNNIO BEZERRA**

\section{RESUMO}

O objetivo desta pesquisa é verificar se o desempenho dos indicadores de bem-estar social dos municípios de Minas Gerais que receberam royalties da mineração são maiores em relação aos que não receberam, a fim de avaliar se a compensação financeira recebida pela exploração de minérios está sendo investida em desenvolvimento econômico e social para as gerações futuras. Utilizou-se do método hipotético-dedutivo com características quantitativa-descritivas na análise e na interpretação dos dados sobre a gestão de 831 municípios de Minas Gerais, em especial, dos municípios arrecadadores da Compensação Financeira pela Exploração Mineral (CFEM). Os resultados demonstraram a existência de relacionamento positivo e significativo entre a presença da CFEM e um maior bem-estar social em relação ao Índice Firjan de Desenvolvimento Municipal e em relação ao PIB per capita.

Palavras-chave: CFEM. Bem-Estar Social. Desenvolvimento Econômico.

\section{ABSTRACT}

The objective of this research is to verify if the performance of the social welfare indicators of the municipalities of Minas Gerais that received mining royalties are higher than those that did not receive, in order to assess whether the financial compensation received for the exploration of minerals is invested in economic and social development for future generations. It used the hypothetical-deductive method with quantitative-descriptive characteristics in the analysis and interpretation of data on the management of 831 municipalities in Minas Gerais, especially the municipalities that collect the Financial Compensation for Mineral Exploration (CFEM). The results demonstrated the existence of a positive and significant relationship between the presence of CFEM and greater social well-being, in relation to the Firjan Municipal Development Index and in relation to GDP per capita.

Keywords: CFEM. Social Welfare. Economic Development.

Recebido em: 03-07-2020 Aceito em: 23-04-2021

\section{INTRODUÇÃO}

A indústria extrativista mineral brasileira, exceto petróleo e gás, tem expressiva representatividade na economia do País. Seu superávit, em 2013, foi equivalente a 4\% do PIB nacional (PORTAL BRASIL, 2014). Está na Constituição Federal de 1988, em seu artigo 20, inciso IX, a declaração de que os recursos minerais, inclusive, do subsolo, são bens da União, e ela assegura, em seu parágrafo 1ำ que o Estado terá participação no resultado da exploração desses bens. O Decreto no 1 , de 1991, regulamenta essa participação que acontece, através da Compensação Financeira pela Exploração Mineral (CFEM), cujas alíquotas variam de $0,2 \%$ a $3 \%$. Também, estabelece esse diploma legal que os Municípios produtores receberão $65 \%$ da arrecadação dos Estados e do Distrito Federal, 23\%, e da União, 12\%.

A preocupação com sustentabilidade econômica de gerações que dependem da indústria extrativista não é recente. Em 1931, Harold Hotelling difundiu uma teoria, conhecida como Renda de Hotelling, a qual preconiza que a exploração de ativos minerários deve ter um custo de uso, uma compensação financeira que refreie uma extração exacerbada pelos exploradores de uma geração, aumentando a vida útil da jazida para gerações futuras (TINOCO; LUSTOSA, 2008). Complementando esse entendimento, outro pesquisador, o economista J. Hartwick apregoou que a imposição de uma taxa, por si só, não garante a sustentabilidade econômica de gerações futuras. Não basta que o Estado cobre pela exploração mineral, como recomenda a renda de Hotelling, é necessário que essa renda seja investida em desenvolvimento que venha garantir o

\footnotetext{
"Mestre em Ciências Contábeis pela Fundação Instituto Capixaba de Pesquisas em Contabilidade, Economia e Finanças - FUCAPE. Pós-graduada em Auditoria Tributária pela Universidade Federal do Rio de Janeiro - UFRJ.

" Doutor e Mestre em Controladoria e Contabilidade pela Universidade de São Paulo. Professor Associado no Programa de PósGraduação em Ciências Contábeis da FUCAPE Business School. E-mail: francisco@fucape.br
} 
bem-estar social, teoria conhecida como a Regra de Hartwick. (POSTALI; NISHIJIMA, 2008).

Os royalties da mineração, no Brasil, concentram-se em 10 dos estados da federação, sendo o Estado de Minas Gerais o maior arrecadador da receita oriunda dessa exploração, a CFEM. Enríquez (2008) pesquisou 15 municípios mineradores no Brasil e 04 canadenses. Seus estudos mostraram a importância da CFEM, na economia daqueles municípios, mas constataram que benefícios concretos dependem de diretrizes administrativas desses recursos.

Draibe e Riesco (2011) identificaram uma relação entre o bem-estar social, desenvolvimento econômico e os indicadores PIB per capita e Índice Firjan de Desenvolvimento Municipal (IFDM) ao estudarem estados de bem-estar social e estratégias de desenvolvimento. Esse relacionamento foi corroborado por Albuquerque et al. (2017) em suas pesquisas sobre as desigualdades regionais na saúde.

O estudo de Postali e Nashijima (2011) utilizou o Índice Firjan de Desenvolvimento Municipal (IFDM), uma referência para discutir a distribuição das rendas do petróleo e os indicadores de desenvolvimento municipal no Brasil, nos anos 2000. Sendo assim, pode-se elaborar a seguinte hipótese de pesquisa: existe relacionamento positivo significativo entre a presença de royalties de minério e o aumento do bemestar social.

Essa pesquisa se propôs a investigar se os indicadores de bem-estar social dos municípios produtores de minérios são alicerçados por investimentos que venham causar efeitos de transbordamento para segmentos diferentes do extrativismo mineral, que, por serem finitos, não são garantia de perpetuidade econômica para futuras gerações. A responsabilidade do gestor como agente de promoção de uma cadeia em que a indústria de inovação, a partir dos anseios da indústria extrativista mineral, beneficie e fomente outros segmentos econômicos que produzirão receitas próprias e autonomia fiscal, precisa ser discutida. Assim, o problema de pesquisa que se busca responder é: os indicadores de bem-estar social são impactados positiva e significativamente nos municípios mineiros que recebem a compensação financeira pela exploração mineral?

Dessa forma, o objetivo desta pesquisa é verificar se o desempenho dos indicadores de bem-estar social dos municípios de Minas Gerais que receberam royalties da mineração são maiores em relação aos que não receberam, a fim de avaliar se a compensação financeira recebida pela exploração está sendo investida em desenvolvimento econômico e social para as gerações futuras. Em outras palavras, se a governança pública, sob a ótica da nova função do Estado, prima em convergir esforços junto a empresas e à sociedade civil, com vistas a investir em soluções para um futuro sustentável (KISSLER; HEIDEMANN, 2006).

\section{REFERENCIAL TEÓRICO}

\subsection{Exaustão dos recursos minerais e seus efeitos para gerações futuras}

Os efeitos de transbordamento que os investimentos em inovação podem trazer aos municípios mineradores são reflexos de uma boa governança pública. Matias-Pereira e Kruglianskas (2005) afirmam serem os investimentos, nessa área, uma constatação do papel geracional do Estado, posto que o desenvolvimento socioeconômico diversificado possibilita redução da dependência econômica desses municípios, por estarem atrelados, predominantemente, à indústria da mineração.

Na governança pública, espera-se do Estado que sua responsabilidade de garantia de bem-estar esteja vinculada ao papel de mediador e de promotor de ações, quer seja por iniciativa própria, quer seja como facilitador de iniciativas privadas (MATIAS-PEREIRA, 2010).

Fazer com que o custo de uso, que é imposto à indústria extrativista, com fins de inibir uma exploração exacerbada, defendido por Hotelling (1931), se converta em investimentos que perpetuem o consumo de gerações futuras (HARTWICK, 1977) é inerente à expectativa de cumprir o desafio atribuído ao Estado, de aplicação adequada das rendas oriundas dos recursos naturais (PAMPLONA; CACCIAMALI, 2017).

Postali e Nishijima (2008) trazem uma boa discussão para o tema, pois a teoria diz que, se a renda for absorvida e não investida, quando da exaustão do patrimônio natural, o consumo será afetado e, consequentemente, haverá queda do bem-estar social. Contudo, se o recurso exaurível for substituído por capital reprodutível, as gerações futuras não serão afetadas (ASHEIM, 2011), o que Costa e Santos (2013), ao estudaram a necessidade de se exercer as justiças intra e intergeracional, concluíram não ser tarefa fácil. Contudo, consideraram imprescindível que se estabeleça a sustentabilidade integral, cujos direitos fundamentais das gerações futuras sejam preservados.

PIB per capita e Índice Firjan de Desenvolvimento Municipal (IFDM) são largamente utilizados pela literatura para espelhar o desenvolvimento econômico dos municípios no Brasil. Em seus estudos sobre os efeitos dos royalties petrolíferos no PIB per capita, dos municípios do estado do Espírito Santo, Ribeiro, Teixeira e Gutierrez (2010) declararam que o PIB per capita é um indicador que reflete o crescimento econômico de uma população, representando uma das formas de se conhecer o resultado de políticas públicas. 
Por sua vez, Massardi e Abrantes (2015), ao estudarem, nos municípios de Minas Gerais, as relações entre esforço fiscal, nível de dependência com o Fundo de Participação dos Municípios (FPM) e desenvolvimento socioeconômicos, utilizaram-se do Índice Firjan de Desenvolvimento Municipal (IFDM) como uma proxy desse desenvolvimento, cujos resultados demonstraram haver baixo nível de esforço fiscal e alto de dependência do FPM, em especial, nos municípios pequenos, com até 5.000 habitantes e com arrecadação inferior a 1\% da receita total (GALVARRO; BRAGA; FONTES, 2008) e pouco industrializados.

Constantino, Pegorare e Da Costa (2016) concluíram, em suas pesquisas, que o mapeamento dos indicadores IDH e PIB pode, efetivamente, auxiliar a solucionar as questões sociais locais, quando constataram que os municípios do Mato Grosso do Sul, entre 2000 e 2010, que mais progrediram no que tange à redução das desigualdades socioeconômicas foram os que apresentavam, anteriormente, os piores indicadores.

Avelino, Bressan e Da Cunha (2013) afirmam que, quando se trata de medir o nível de desenvolvimento de uma sociedade, o Índice FIRJAN de Desenvolvimento Municipal (IFDM) equivale ao Índice de Desenvolvimento Humano Municipal (IDH-M).

Postali e Nishijima (2011) utilizaram-se do Índice Firjan de Desenvolvimento Municipal (IFDM) para avaliar o grau de dependência dos municípios brasileiros em relação aos royalties petrolíferos e concluíram que, quanto mais dependente dos royalties do petróleo for o município, menor é o Índice Firjan de Desenvolvimento Municipal (IFDM), quando comparados à média nacional.

Também relacionado ao desenvolvimento econômico está a gestão ambiental, que, no estudo de Enríquez (2009) sobre a possibilidade de conciliar mineração e o desenvolvimento sustentável, constata-se que a gestão ambiental, com a adoção de padrões mais restritos, é um aspecto positivo considerado pelas empresas que implementam esse sistema de gestão, tendo, este, influência no desempenho econômico das instituições. Nossa (2002) torna evidente a importância das informações ambientais, quando declara que a divulgação dessas informações nos relatórios das empresas privadas precisa de padronização e credibilidade para atender aos stakeholders.

Tridapalli et al. (2011) procuraram levantar as mais importantes formas de analisar os gastos ambientais no setor público, de maneira que, se pudesse, a partir de maior transparência dos dados, conseguir avaliações que levassem a conhecer a efetividade das políticas ambientais. Destacaram os autores que, no âmbito internacional, é frequente o uso de indicadores econômicos para análise dos gastos ambientais, e, em especial, os do setor público, na participação no PIB.

O equilíbrio fiscal das gestões dos municípios brasileiros foi objeto de estudo de Melo, Souza e Bonfim (2015), que, utilizando-se do Índice Firjan de Gestão Fiscal (IFGF) dos anos de 2007 e 2008, foi possível fazer análises comparativas importantes sobre a saúde fiscal dos municípios brasileiros. Os autores evidenciaram que tal índice permitiu analisar os aspectos mais relevantes publicados na literatura quanto à função e ao desempenho dos governos municipais.

Helou Filho e Otani (2007) estudaram sobre as ferramentas que auxiliam o gestor público a contornar problemas sociais no Estado de Santa Catarina e concluíram que, quando aumentarem os índices de desenvolvimento, se torna um alvo da administração. Ela conquista redução de níveis de desigualdades, uma vez que as políticas voltadas para a melhoria dos indicadores elevam a qualidade de vida da população e, consequentemente, uma evolução qualitativa na gestão pública.

Fazer com que a CFEM, ou seja, o custo de uso, que é imposto à indústria extrativista, com fins de inibir uma exploração exacerbada, defendido por Hotelling (1931), se converta em investimentos que perpetuem o consumo de gerações futuras (Hartwick, 1977). É inerente à expectativa de cumprir o desafio atribuído ao Estado de aplicação adequada das rendas oriundas dos recursos naturais (Pamplona \& Cacciamali, 2017).

Postali e Nishijima (2008) trazem uma boa discussão para o tema, pois a teoria diz que, se a renda for absorvida e não investida, quando da exaustão do patrimônio natural, o consumo será afetado e, consequentemente, haverá queda do bem-estar social. Contudo, se o recurso exaurível for substituído por capital reprodutível, as gerações futuras não serão afetadas (Asheim, 2011), o que Costa \& Santos (2013), ao estudaram a necessidade de se exercer as justiças intra e intergeracional, concluíram não ser tarefa fácil. Contudo, consideraram imprescindível que se estabeleça a sustentabilidade integral em que os direitos fundamentais das gerações futuras sejam preservados.

\subsection{Desenvolvimento econômico}

Para Jorge e Dantas (2009), o PIB teve grande peso no crescimento de diversos países no cenário internacional. Sua pesquisa avaliou a interação entre o investimento estrangeiro direto, o transbordamento e a produtividade industrial, e concluiu que as diferenças entre os diversos setores industriais devem ser consideradas, dada a heterogeneidade dos segmentos, para que os resultados de transbordamentos possam ser bem calculados e permitam identificar os efeitos de desenvolvimento de forma seletiva. 
Massardi e Abrantes (2015) demonstraram haver baixo nível de esforço fiscal e alto de dependência do FPM ao estudarem nos municípios de Minas Gerais, as relações entre esforço fiscal, nível de dependência com o Fundo de Participação dos Municípios (FPM) e desenvolvimento socioeconômicos, tendo, no Índice Firjan de Desenvolvimento Municipal (IFDM), um indicativo desse desenvolvimento.

O IFDM contribui para a gestão pública no sentido de direcionar suas ações, posto que analisa os impactos sobre o desenvolvimento dos municípios, constituindo-se em um instrumento precioso, tanto para a gestão quanto para a sociedade, uma vez que facilita a accountability no processo democrático (FIRJAN, 2014). Suas fontes são estatísticas públicas oficiais divulgadas pelos ministérios da Saúde, da Educação e do Trabalho. Adota uma metodologia que permite determinar que, em havendo melhora relativa do índice de determinado município, essa é provocada pelas políticas públicas implementadas e não em consequência da decadência de outros municípios (FIRJAN, 2018).

O estudo de Enríquez (2009) sobre a possibilidade de conciliar mineração e o desenvolvimento sustentável constatou que a gestão ambiental, com a adoção de padrões mais restritos, é um aspecto positivo considerado pelas empresas que implementam esse sistema de gestão, tendo, este, influência no desempenho econômico das instituições. Tridapalli et al. (2011), ao estudarem sobre gastos ambientais governamentais, destacaram que, no âmbito internacional, é frequente o uso de indicadores econômicos para análise dos gastos ambientais, e, em especial, os do setor público na participação no PIB.

O estudo de Gadelha (2012) defende que a relação entre saúde e desenvolvimento é indissociável, a ponto de afirmar que, em países desenvolvidos, não há precariedade no sistema de saúde. Seu trabalho afirma que, nessa relação, deve-se ater, primordialmente, a duas abordagens. A primeira diz respeito à saúde como direito civil universal do indivíduo, já defendido remotamente pelo Fundo Monetário Internacional (FMI) e o Banco Mundial de Desenvolvimento (BIRD), para que o Estado forneça a proteção social através de compromissos governamentais ao instituir e manter políticas públicas que lhe ofereçam, além de dignidade, condições para o mercado de trabalho. A segunda está relacionada ao incremento à inovação e manutenção da base produtiva de bens e serviços das diversas atividades econômicas da área de saúde, de forte influência no PIB e nos empregos formais. Ao estudar as empresas manufatureiras no Brasil, Paula e Silva (2018) mostraram que, quando há investimento em Pesquisa \& Desenvolvimento externa, qual seja, aquela oriunda de parcerias com outras organizações, há, também, uma relação positiva no desempenho da inovação.

Já os estudos de Heller (1998) faz uma relação entre saúde e saneamento no contexto do desenvolvimento social, deixando evidente o vínculo existente entre saneamento e desenvolvimento. Seus achados afirmam haver maior desenvolvimento nos países em que a sociedade tem alto atendimento de serviços de saneamento e, consequentemente, populações mais saudáveis, sendo esse resultado, independente dos demais, um indicador de desenvolvimento social.

Para medir o equilíbrio fiscal das gestões dos municípios brasileiros, Melo, Souza e Bonfim (2015) utilizaram o Índice Firjan de Gestão Fiscal (IFGF) dos anos de 2007 e 2008, que, segundo os autores, propicia análises comparativas importantes sobre a saúde fiscal dos municípios brasileiros. Luque e Silva (2004) atribuíram a tendência a situações crônicas de desiquilíbrio orçamentário à condição de mais um item de "falhas de governo", em especial, em países não desenvolvidos, que são mais propensos a apresentar demandas de despesas muito maiores que as de possíveis receitas. Tal constância de desiquilíbrios orçamentários tende a reduzir o nível de confiabilidade da gestão. Entenderam os autores que, por esse motivo, a Lei de Responsabilidade Fiscal (LRF) se apresenta como uma ferramenta para gestão fiscal que obriga a divulgação de objetivos, metas e indicadores expressos com clareza para fácil acompanhamento do desempenho da gestão.

\subsection{Crescimento econômico e investimentos}

O estudo de Bogoni, Hein e Beuren (2011) mostrou que o provimento de serviços públicos afeta, tanto a qualidade de vida da população quanto a produtividade das empresas, por isso afirma haver uma relação entre gastos públicos, bem-estar social e crescimento econômico. O estudo analisou, ainda, a relação entre crescimento econômico e gastos públicos com investimentos nas maiores cidades do sul do Brasil, e concluiu que esta relação é positiva. Seu trabalho encontrou evidências de que, mesmo existindo um limite para o efeito positivo do gasto com capital sobre o crescimento, os estados brasileiros, à exceção de Tocantins, ainda investem abaixo do esperado.

Quando Gadelha (2012) estudou sobre desenvolvimento e saúde, analisou as ações governamentais em duas abordagens: uma apontou o Estado como paternalista, em que há a obrigação de mantenedor de proteção social por meio de políticas públicas e, numa segunda, retratou as novas funções do governo de promotor, incentivador e articulador de ações que estimulem a inovação e a produção de bens e serviços de diferentes segmentos econômicos e sociais. O estímulo a essa articulação de parcerias encontra eco no resultado do trabalho de Paula e Silva (2018), que, ao estudarem as empresas manufatureiras no Brasil, evidenciaram que, quando há investimento em Pesquisa \& Desenvolvimento externa, qual seja, aquela 
oriunda de parcerias com outras organizações, há, também, uma relação positiva no desempenho da inovação.

A atenção especial que os Municípios mineradores precisam receber fica bem explícita na Constituição do Estado de Minas Gerais. Em seu artigo 253, a Carta Magna Estadual estabelece que o governo de Minas Gerais dará assistência diferenciada aos Municípios que exercem atividade extrativista mineral, com o intuito de diversificar sua economia e garantir a aplicação da renda de Hartwick, qual seja, sustentabilidade socioeconômica para as futuras gerações.

\subsection{Governança pública}

O estudo de Araújo e Silvestre (2014) afirma que o Estado deveria se desincumbir do controle de processos e concentrar seus esforços em sua principal missão, a de observar os resultados das ações implementadas, assegurando que estejam trazendo a eficiência e a efetividade, princípios da gestão pública. Seus achados dizem que as Parcerias Público-Privadas precisam ser bem construídas, atrelando as ações implementadas com os resultados sociais alcançados, o que leva a entender a importância dos princípios da governança, uma vez que associam eficiência administrativa ao bem-estar social, quando alinham os interesses públicos aos privados. (KISSLER; HEIDEMANN, 2006).

Ao avaliar a qualidade dos gastos públicos e seus impactos sobre o crescimento econômico, o estudo de Rocha e Giuberti (2007) trouxe, também sob a ótica da boa gestão, a importância de bem delinear os gastos produtivos e improdutivos. Reconhecidamente, os produtivos, por focarem em investimentos, estarão mais voltados a gerações futuras, diferentemente dos improdutivos que são saneadores de consumos imediatos ou de passivos sociais.

Há uma discussão que os estudos de Pamplona e Cacciamali (2017) trouxeram que ajudam a entender que, nos questionamentos sobre o paradoxo da abundância da indústria extrativista mineral, o Estado tem sua função de gestor potencializada, tendo que avaliar a complexidade da escolha de diversificação da economia para incrementar oportunidades futuras, primordialmente por inovação, contudo sem perda de benefícios já conquistados. Sendo assim, as transparências, equidade, prestação de contas e responsabilidades, princípios elementares da boa governança, têm que compor o processo (MATIASPEREIRA, 2010).

O estudo de Pegg (2006) faz uma análise crítica sobre a relação da exploração mineral e a redução da pobreza, partindo do pressuposto de que os minerais são excelentes fontes de recursos. Todavia, sua pesquisa destaca que a riqueza produzida não é distribuída de forma igualitária, e sim concentrada numa camada da população já privilegiada economicamente, em detrimento da grande massa, que se torna cada vez mais empobrecida. Contudo, em seus estudos sobre os efeitos dos royalties petrolíferos no PIB per capita dos municípios do estado do Espírito Santo, Ribeiro, Teixeira e Gutierrez (2010) declararam que, apesar de controversas, o PIB per capita é, ainda, um indicador que reflete o crescimento econômico de uma população, sendo uma das formas de se conhecer o resultado de políticas públicas.

O autor analisa o papel do Banco Mundial, como o então grande defensor de incentivos à mineração, ao tempo que é, também, responsável por fomentar a redução da pobreza. $O$ trabalho faz uma crítica àquela instituição quando diz que a retórica não corresponde aos fatos, ou seja, o desenvolvimento da exploração mineral não contribuiu para a redução da pobreza, posto que não levou oportunidades de desenvolvimento comuns a toda população. $O$ estudo abordou a mudança de paradigma necessária para que a exploração extrativista mineral venha a ser, de fato, uma contribuição para a redução da pobreza.

Quanto à importância da CFEM para a sustentabilidade econômica regional, os estudos de Amaral Filho (2009) mostraram que a arrecadação de receita local implica desenvolvimento, a partir de uma racionalidade fiscal, quando constataram que, apoiada nessa racionalidade, é possível criar formas de financiamento e de acumulação de capital. Segundo o autor, à medida que o Estado consegue gerar poupança própria, provoca a atração de parcerias, tanto de empresas privadas como de bancos de fomento, como o Banco Mundial. Sendo, em grande parte, a geração de poupança pública local e a capacidade de investimento, o que financiam o papel do Estado de interagir com os parceiros, com fins de atender às demandas sociais.

Ao analisarem a dependência de transferências fiscais e a capacidade de arrecadação dos municípios de Minas Gerais, o trabalho de Galvarro, Braga e Fontes (2008) trouxe como uma das evidências, o fato de que os municípios de pequena captação de receita própria e grandes dependências fiscais têm também baixos índices de desempenho econômico. Essa evidência ganha força nos resultados alcançados por Massardi e Abrantes (2015), que, ao estudarem sobre o efeito do esforço fiscal sobre o desenvolvimento nos municípios de Minas Gerais, concluíram que os de maior desenvolvimento socioeconômico também são os que exibem melhores índices de esforço fiscal. Ao estudarem a função social da exploração mineral no estado de Minas Gerais, Batista Júnior e Silva (2013) declaram que, dentre os princípios gerais constitucionais da atividade econômica, está o dever de melhorar a vida da coletividade. 


\subsection{Atividades inovadoras que venham substituir a indústria extrativista}

Discussões sobre formas de incentivo à inovação tecnológica, no Brasil, tiveram início em 2000, com projetos de lei que culminaram na Lei de Inovação no $10.973 / 2004$, lei de incentivos à inovação e às pesquisas científica e tecnológica no ambiente produtivo.

A Organisation for Economic Co-operation and Development (OECD) emitiu um relatório em que divulga que as novas tecnologias, mesmo em países mais avançados, são subutilizadas pelas empresas, quando poderiam estar contribuindo muito mais em ganho de produtividade (OECD, 2017).

Em Minas Gerais, o projeto Nova Mineração, instituído pela Fundação de Amparo à Pesquisa do Estado de Minas Gerais (Fapemig), tenta motivar a criação de startups associadas à mineração, principalmente, no quadrilátero ferrífero do estado.

Para Matias-Pereira e Kruglianskas (2005), a inovação tecnológica deve pr,omover a integração de vários agentes em frentes diferenciadas, a fim de levar as potencialidades científicas a suprir as necessidades econômicas e sociais, cabendo ao Estado o papel de articular esse processo de inovação. O Plano de Negócios do programa INOVA Mineral, realizado pelo Banco Nacional de Desenvolvimento Social (BNDES), em conjunto com Financiadora de Estudos e Projetos (FINEP, 2017), evidencia que os investimentos em inovação do programa são voltados, exclusivamente, para esse segmento econômico, mineração. Silva, Curi e Flores (2012) explicam que existe uma necessidade de os municípios diversificarem seus investimentos, desprendendo-se da dependência do setor mineral, dada a natureza finita da arrecadação da CFEM.

\section{METODOLOGIA}

Esta pesquisa pode ser classificada como descritiva quantitativa e foi realizada por meio de levantamento bibliográfico. A análise foi feita com dados combinados e organizados em painel desbalanceado, pois o número de observações não é o mesmo para todos os municípios (GUJARATI; PORTER, 2011). A pesquisa buscou dados referentes às variáveis independentes que influenciam as variáveis dependentes IFDM e PIB per capita representantes, nesse modelo, do bem-estar social, no período de 2007 a 2013. Às variáveis PIB per capita e CFEM foi aplicado o logaritmo neperiano, o que permitiu ajustar sua distribuição (SPOHR; FREITAS, 2011).

Observa-se que a divulgação do IFDM foi publicada até 2013 e a ausência, total ou parcial de publicação das Demonstrações Contábeis de 22 prefeituras, reduziu o número de municípios de 853 para 831 do estado de Minas Gerais, principal arrecadador dos royalties da mineração no Brasil (VIANA; BURSZTYN, 2010). Por fim, a análise da pesquisa compara o comportamento do bem-estar social dos 494 municípios arrecadadores com os 337 municípios que recebem a receita dos royalties.

O quadro 1 descreve as variáveis inseridas no modelo, as fontes de dados utilizadas, uma descrição e as referências que suportam sua utilização nesse trabalho.

Quadro 1 - Variáveis e Fontes de dados

\begin{tabular}{|l|c|l|l|}
\hline \multicolumn{1}{|c|}{ Variável } & Fonte & \multicolumn{1}{|c|}{ Descrição } & \multicolumn{1}{|c|}{ Referências } \\
\hline IFDM & FIRJAN & $\begin{array}{l}\text { Índice Firjan de Desenvolvimento Municipal. } \\
\text { Acompanha, anualmente, desenvolvimento } \\
\text { socioeconômico dos municípios brasileiros }\end{array}$ & $\begin{array}{l}\text { Postali } \\
\text { Nashijima (2011) }\end{array}$ \\
\hline PIB per capita & $\begin{array}{l}\text { IBGE- } \\
\text { SIDRA }\end{array}$ & $\begin{array}{l}\text { Produto Interno Bruto relativizado pela população } \\
\text { municipal }\end{array}$ & $\begin{array}{l}\text { Albuquerque et al. } \\
(2017)\end{array}$ \\
\hline CFEM & DNPM & $\begin{array}{l}\text { Compensação Financeira pela Exploração } \\
\text { Mineral (royalties da mineração) }\end{array}$ & Enríquez (2008) \\
\hline IFGF & FIRJAN & $\begin{array}{l}\text { Avalia como os recursos públicos são } \\
\text { administrados pelas prefeituras }\end{array}$ & $\begin{array}{l}\text { Melo, Souza e } \\
\text { Bonfim (2015) }\end{array}$ \\
\hline $\begin{array}{l}\text { GESTÃO } \\
\text { AMBIENTAL }\end{array}$ & $\begin{array}{c}\text { SICONFI/ } \\
\text { Compara } \\
\text { Brasil }\end{array}$ & $\begin{array}{l}\text { Gastos efetuados pelas prefeituras para atender } \\
\text { às questões ambientais }\end{array}$ & $\begin{array}{l}\text { Tridapalli et al. } \\
(2011)\end{array}$ \\
\hline SAÚDE & $\begin{array}{l}\text { SICONFI/ } \\
\text { Compara } \\
\text { Brasil }\end{array}$ & $\begin{array}{l}\text { Recursos investidos pelas prefeituras no } \\
\text { atendimento à saúde pública }\end{array}$ & $\begin{array}{l}\text { Albuquerque et al. } \\
(2017)\end{array}$ \\
\hline
\end{tabular}


A fórmula 1 representa o modelo associado à problemática desse estudo considerando o Índice Firjan de Desenvolvimento Municipal:

$$
I F D M_{i t}=\beta_{0}+\beta_{1} C_{F E M}+\beta_{2} I F G F_{i t}+\beta_{4} S A U ́ D E_{i t}+\beta_{5} G A M B_{i t}+\varepsilon_{i t}(1)
$$

IFD $\boldsymbol{M}_{i t}$ - Retrata o Índice Firjan de Desenvolvimento Municipal do i-ésimo município no ano t;

$\boldsymbol{C F E}_{\boldsymbol{i t}}$ - Logaritmo neperiano da CFEM no i-ésimo munícipio no ano t, onde 1 (um) recebeu Compensação Financeira pela Exploração Mineral e 0 (zero) caso contrário; $\boldsymbol{I F G}_{\boldsymbol{G}}$ - Expressa o Índice Firjan de Gestão Fiscal do i-ésimo município estudado, no ano t;

$\boldsymbol{S A U D E _ { i t }}$ - Reflete, em logaritmo neperiano, dispêndio em Saúde do i-ésimo município no ano t;

$\boldsymbol{G A M B}_{i t}$ - Demonstra, em logaritmo neperiano, desembolso com Gestão Ambiental do i-ésimo município no ano t;

$\varepsilon_{i t}$ - Define o erro aleatório.

A fórmula 2 representa o modelo associado à problemática desse estudo considerando o PIB per capita:

$$
\text { PIBper }_{i t}=\beta_{0}+\beta_{1} \text { CFEM } M_{i t}+\beta_{2} I F G F_{i t}+\beta_{4} S A U ́ D E_{i t}+\beta_{5} G A M B_{i t}+\varepsilon_{i t}(2)
$$

PIBper $_{i t}$ - Logaritmo neperiano do PIB per capita do i-ésimo município no ano t;

$\boldsymbol{C F E M}_{i t}$ - Logaritmo neperiano da CFEM no i-ésimo munícipio no ano $\mathrm{t}$, onde 1 (um) recebeu Compensação Financeira pela Exploração Mineral e 0 (zero) caso contrário;

$I F G F_{i t}$ - Expressa o Índice Firjan de Gestão Fiscal do i-ésimo município estudado, no ano t;

$\boldsymbol{S A U D E _ { i t }}$ - Reflete, em logaritmo neperiano, os gastos em Saúde do i-ésimo município no ano t;

$\boldsymbol{G A M B}_{\text {it }}$ - Demonstra, em logaritmo neperiano, o desembolso com Gestão Ambiental do i-ésimo município no ano t;

$\mathcal{E}_{i t}$ - Define o erro aleatório.

Pelo estudo do coeficiente da CFEM $\left(\boldsymbol{\beta}_{\mathbf{1}}\right)$ será possível avaliar, estatisticamente, se a CFEM interfere, de forma significativa, nas proxies de bem-estar social (IFDM e PIB per capita).

\section{ANÁLISE DOS RESULTADOS}

A pesquisa analisou 4.961 observações em dois grupos. Um de 494 municípios que recebem a compensação (2.168 observações), e outro de 337 que não recebem (2.793 observações).

Tabela 1 - Estatística Descritiva dos Indicadores

\begin{tabular}{lcccc}
\hline \multirow{2}{*}{ Variáveis } & \multicolumn{4}{c}{ Compensação Financeira pela Exploração Mineral (CFEM) } \\
\cline { 2 - 5 } & \multicolumn{2}{c}{$\operatorname{Sim}(\mathrm{n}=2.168)$} & \multicolumn{2}{c}{ Não $(\mathrm{n}=2.793)$} \\
\cline { 2 - 5 } & \multicolumn{1}{c}{ Média } & Desvio padrão & Média & Desvio padrão \\
\hline IFDM & 0,667029 & 0,088684 & 0,602107 & 0,088452 \\
\hline PIB per capita & 9,330528 & 0,662942 & 8,859921 & 0,543508 \\
\hline IFGF & 0,526710 & 0,131182 & 0,483747 & 0,121742 \\
\hline GAMB & 7,989117 & 5,414341 & 5,616130 & 5,072760 \\
\hline SAUDE & 15,603740 & 1,188980 & 14,788180 & 0,596413 \\
\hline
\end{tabular}

Fonte: Dados da pesquisa.

No que diz respeito ao IFDM, a média da amostra dos que arrecadam CFEM foi de 0,66, e a amostra dos municípios que arrecadam ficou em 0,60. Em uma análise descritiva, a média dos municípios de base mineradora é superior em 10,8\% a dos municípios que não se beneficiam da compensação.

Quanto ao PIB per capita, o primeiro grupo exibiu um valor médio maior em 5,3\% em relação ao segundo grupo. Quando a análise recaiu sobe as variáveis de controle, os municípios de base mineradora novamente tiveram médias superiores aos não mineradores, sendo: Índice Firjan de Gestão Fiscal (IFGF), com médias superiores em 8,88\% e Saúde (SAUDE) em 5,51\%. Destacou-se, das demais ocorrências, a variação das médias de Gestão Ambiental (GAMB), que excedeu em 42,25\% em relação aos não arrecadadores da CFEM.

A análise dos resultados da correlação de Pearson identificou que todas as variáveis se mostraram correlacionados ao nível de $5 \%$ de significância com a variável de pesquisa CFEM. 


\subsection{Estimativa de regressão com dados em painel desbalanceado (Dados Empilhados) - IFDM}

Para verificar a homocedasticidade dos erros da regressão que possui como variável dependente o IFDM, o resultado do teste de Breusch-Pagan indicou que os erros da regressão são heterocedásticos, ou seja, possuem variâncias diferentes. Dessa forma, para a regressão ser validada e possibilitar a análise, ela foi ajustada por erros-padrão robustos de White (GUJARATI; PORTER, 2011).

Em relação à normalidade da distribuição, cuja coleta de dados produziu 4.896 observações, foi aceito o pressuposto de normalidade fundamentado pelo teorema do limite central, o qual dita que grandes amostras tendem à normalidade (MACEDO; MACHADO; MACHADO, 2013).

O último pressuposto analisado foi o da multicolinearidade por meio do Fator de Inflação da Variância (FIV), cujo maior resultado foi de 1,46, demonstrando que não há problema de multicolinearidade entre as variáveis, pois, segundo Melo, Souza e Bonfim (2015), ele só ocorre quando o FIV é superior a 10.

Para averiguar se as variáveis são significativas no modelo e se explicam a variação no índice IFDM, foi efetuada a regressão e a análise de seus resultados.

Tabela 2 - Regressão IFDM por Dados Empilhados por Erros-Padrão Robusto

\begin{tabular}{|c|c|c|c|c|c|c|}
\hline Observações & \multicolumn{2}{|c|}{4.896} & & & & \\
\hline Teste F $(4,4891)$ & \multicolumn{2}{|c|}{655,19} & & & & \\
\hline P-Valor do Teste F & \multicolumn{2}{|c|}{$<0,0001$} & & & & \\
\hline $\mathrm{R}^{2}:$ & \multicolumn{2}{|c|}{27,03} & & & & \\
\hline IFDM & Coef. & Erro Padrão & $t$ & P-valor $|\mathbf{t}|$ & \multicolumn{2}{|c|}{ Intervalo de Confiança 95\% } \\
\hline CFEM & 0,0032429 & 0,0002538 & 12,78 & 0,000 & 0,0027452 & 0,0037405 \\
\hline IFGF & 0,0586733 & 0,0092605 & 6,34 & 0,000 & 0,0405186 & 0,0768280 \\
\hline Gamb & 0,0011532 & 0,0002457 & 4,69 & 0,000 & 0,0006716 & 0,0016349 \\
\hline Saude & 0,0325863 & 0,0012854 & 25,35 & 0,000 & 0,0300664 & 0,0351062 \\
\hline cons & 0,0866197 & 0,0183242 & 4,73 & 0,000 & 0,0506959 & 0,1225434 \\
\hline
\end{tabular}

Fonte: Dados da pesquisa.

As variáveis independentes explicam em torno de $27 \%$ das alterações da variável dependente IFDM. Observa-se que todas as variáveis possuem relação com o índice IFDM. Os resultados indicaram que, ao nível de significância de 5\%, tanto a variável CFEM quanto as variáveis de controle foram estatisticamente significativas.

Pode-se afirmar que, a cada $1 \%$ de aumento da CFEM, há um incremento de 0,003\% no IFDM, resultado que corrobora com a pesquisa de Enríquez (2008), que, também, concluiu haver influência positiva da receita de royalties sobre o desenvolvimento humano. Enríquez (2008) enfatiza que a existência dessa compensação mineral, no Brasil (diferentemente do Canadá, onde há um instrumento específico para recuperação ambiental), é um meio de aplacar a crise socioeconômica que a exaustão dos recursos naturais ocasiona, isso se medidas de investimentos, em capital produtivo, forem tomadas.

\subsection{Estimativa de regressão com dados empilhados - PIB per capita}

Assumiu-se o pressuposto de normalidade pela grande quantidade de observações (4.914) tratadas no estudo (MACEDO; MACHADO; MACHADO, 2013). Procedeu-se, então, à análise, depois de ajustes por erros-padrão robustos de White. (GUJARATI; PORTER, 2011).

Tabela 3 - Regressão PIB per capita por Dados Empilhados

\begin{tabular}{lc}
\hline Observações & 4.914 \\
\hline Teste $F(4,4909)$ & 535,37 \\
\hline $\mathrm{P}$-Valor do Teste $\mathrm{F}$ & $<0,0001$ \\
\hline $\mathrm{R}^{2}:$ & 32,62
\end{tabular}

\begin{tabular}{l|c|c|c|c|cc}
\hline \multicolumn{1}{l}{ PIB per capita } & \multicolumn{1}{c}{ Coef. } & \multicolumn{1}{c}{ Erro Padrão } & \multicolumn{1}{c}{ T } & \multicolumn{2}{c}{ P-valor $|\mathbf{t}|$} & \multicolumn{2}{c}{ Intervalo de Confiança 95\% } \\
\hline CFEM & 0,0296370 & 0,0019754 & 15,00 & 0,000 & 0,0257642 & 0,0335098 \\
\hline IFGF & 0,1812149 & 0,0640700 & 2,83 & 0,005 & 0,0556090 & 0,3068207 \\
\hline Gamb & 0,0076927 & 0,0016037 & 4,80 & 0,000 & 0,0045486 & 0,0108368 \\
\hline Saude & 0,2387806 & 0,0097808 & 24,41 & 0,000 & 0,2196058 & 0,2579554 \\
\hline Cons & 5,1839960 & 0,1388726 & 37,33 & 0,000 & 4,9117430 & 5,4562480 \\
\hline
\end{tabular}

Fonte: Dados da pesquisa. 
O modelo preditivo evidencia que as variáveis independentes foram significativas a $5 \%$ e explicaram, aproximadamente, $32 \%$ das variações ocorridas no PIB per capita. A evidência é de que, pelo coeficiente da variável CFEM, a cada $1 \%$ de aumento na arrecadação dos royalties, o PIB per capita aumenta $0,03 \%$, o que permite concluir que o crescimento econômico é favorecido pela existência dessa receita, achado esse que também converge com os resultados de Enríquez (2008), quando afirma que tal crescimento ocorrerá enquanto subsistirem os recursos minerários.

Já os estudos, Rodrigues, Moreira e Colares (2016), em um corte transversal de 10 municípios, consideram que a dependência da CFEM acarreta redução do desenvolvimento humano, não evidenciados em nossos trabalhos ou nos achados de Enríquez (2008). Contudo, todas as pesquisas concordam em afirmar que a governança pública, aquela que aponta para a nova função do Estado em investir soluções para um futuro sustentável (KISSLER; HEIDEMANN, 2006), precisa atentar para a necessidade de aplicar os recursos dos royalties em atividades econômicas que assegurem continuidade de consumo quando da exaustão dos recursos naturais.

Tabela 4 - Estatística Descritiva das Despesas: de Capital e Custeio

\begin{tabular}{|c|c|c|c|c|}
\hline \multirow{3}{*}{$\begin{array}{l}\text { Observações: } \\
\begin{array}{ll}\text { Desp. Capital per capita }(n=4895) \\
\text { Custeio per capita } \quad(n=4902)\end{array}\end{array}$} & \multicolumn{4}{|c|}{$\begin{array}{c}\text { Compensação Financeira pela Exploração Mineral } \\
\text { (CFEM) }\end{array}$} \\
\hline & \multicolumn{2}{|c|}{$\operatorname{Sim}(1)$} & \multicolumn{2}{|c|}{ Não $(0)$} \\
\hline & Média & $\begin{array}{l}\text { Desvio } \\
\text { padrão }\end{array}$ & Média & $\begin{array}{l}\text { Desvio } \\
\text { padrão }\end{array}$ \\
\hline Despesas de Capital per capita & 207,13 & 272,65 & $\underline{208,51}$ & 181,30 \\
\hline Custeio per capita & $\underline{1471,05}$ & 777,29 & $\overline{1554,47}$ & 816,01 \\
\hline Relação Desp. Custeio/Despesa de Capital & $7 \overline{10 \text { vezes }}$ & & $7 \overline{45 \text { vezes }}$ & \\
\hline
\end{tabular}

Fonte: Dados da pesquisa

Para que o Estado venha orquestrar seu papel com o do setor privado e o terceiro setor, com fins de tornarem-se efetivas as ações que visam atender à sociedade por meio de um consolidado processo de governança, aquele que introduz mecanismos de desenvolvimento econômico sustentável, é necessário que as rendas provenientes dos recursos exauríveis sejam investidas em bens de capital ou em desenvolvimento tecnológicos que perpetuem o consumo de futuras gerações.

A Tabela 4 apresentou os resultados das Estatísticas Descritivas com as médias das variáveis Despesas de Capital e Custeio, segmentados por grupo de municípios que arrecadam e que não arrecadam a CFEM, relativizados por suas populações. Os resultados mostraram que, tantos os municípios que arrecadam como os que não arrecadam os royalties da mineração, têm as médias das despesas de custeio 7 vezes maiores que as de investimentos em capital físico.

Pelos dados levantados, em ambos os grupos (os que recebem royalties e os que não recebem), empregaram maior parte dos recursos em custeio, o que, para Hartwick (1977), são gastos ineficazes para o desenvolvimento social, uma vez que sua regra postula que os investimentos em capital geram consumo/produção no longo prazo.

Os dois grupos apresentam, proporcionalmente, similaridade na execução dos recursos, visto que as médias dos investimentos em ativos físicos do grupo de base mineradora são inferiores em $0,66 \%$ em relação ao grupo não minerador. Quanto ao custeio, suas médias foram 5,36\%, menores que as do grupo que não tem a indústria extrativista mineral.

Foi efetuado o teste de diferença de médias que confirmou, pela soma dos ranks, que, tanto os gastos com despesas de capital quanto com custeio, são, em média, menores no grupo dos municípios que têm a compensação financeira pela CFEM. Ou seja, ainda que a presença da CFEM tenha influenciado positivamente o bem-estar social no período estudado, os investimentos em ativos físicos e humanos preconizados por Hartwick (1977) e Rocha e Giuberti (2007) para a perpetuidade das futuras gerações precisam ser observados pelas políticas públicas dos municípios mineradores.

\section{CONSIDERAÇÕES FINAIS}

Pode-se concluir que, dos 831 municípios investigados, 494 que recebem os royalties da mineração demonstraram que a existência da compensação financeira vinculada à exploração mineral melhorou os indicadores de bem-estar social, IFDM e PIB per capita.

O resultado mostrou que as variáveis independentes utilizadas no estudo se relacionaram, positivamente, com as variáveis de resposta ao nível de confiança de $95 \%$, indicando a aceitação da hipótese 1 , ou seja, a existência de relacionamento positivo significativo entre a presença de royalties de minério e o aumento do bem-estar social. 
Este estudo se propôs a testar se existe um relacionamento positivo e significativo entre a presença de royalties de minério e o aumento do bem-estar social, os quais foram confirmados pelos resultados da pesquisa. Contudo, no que tange à sustentabilidade para gerações futuras, no seu sentido mais amplo, como no estudo de Enríquez (2009), as condições socioeconômicas satisfatórias são, ainda, um problema a ser solucionado pelos agentes públicos. Como retratado nos trabalhos de Costa e Santos (2013), o desenvolvimento econômico que promova a sustentabilidade de uma geração deve produzir riquezas tais que garantam a sustentabilidade das gerações futuras.

Esse trabalho contribui para evidenciar que os municípios que recebem a compensação financeira (CFEM) não apresentaram diferencial em investimentos em relação aos municípios que não contam com tal receita, e, sendo os investimentos promotores de desenvolvimento (BOGONI; HEIN; BEUREN, 2011), os resultados trazem luz à obrigação do Estado em cumprir seu papel de assegurar o bem-estar social, dando eficácia aos recursos auferidos, impelindo-os a reduzir a acomodação à dependência de recursos exauríveis, como a os da mineração, que podem ser concretizada pelo efeito de transbordamento ao se utilizar os recursos em investimentos diferenciados.

Dado o poder discricionário do gestor e a condição de receita não vinculada da CFEM, são imprescindíveis o fomento de ferramentas de governança que preconize o Compliance e a Accountability, em que a sociedade possa acompanhar o cumprimento da Constituição do Estado de Minas Gerais, que estabelece que o investimento da CFEM seja voltado para empreendimentos diversificados, não dependentes da indústria extrativista, ante a natureza exaurível dos recursos naturais, sendo o gestor responsabilizado pelo não cumprimento. Seria, também, atendido o princípio da equidade, se considerarmos que, pelo efeito de transbordamento, as camadas da sociedade que não são diretamente beneficiadas pela exploração mineral serão alcançadas pela introdução de novas tecnologias e de novos mercados.

Pesquisas futuras poderão verificar projetos específicos que alterem o comportamento dos índices de bem-estar social, como o aumento do grau de investimentos em inovação científica ou tecnológica realizada nos municípios, que, atualmente, têm sua economia calcada na exploração extrativista de minério. Também, poderá ser objetivo de futuros estudos, o montante da arrecadação dos royalties que foi empregado em investimentos dissociados à mineração.

Pode-se considerar limitações desse trabalho o fato de termos a publicação do IFDM até 2013. Além disso, o fato de se ter avaliado, apenas, a questão de um tipo de benefício relacionado à extração de minérios. As proxies utilizadas como métricas de avaliação da evolução do bem-estar social (PIB per capita e IFDM) carregam as limitações da construção dessas duas variáveis.

\section{REFERÊNCIAS}

Albuquerque, M. V. D.; VIANA, A. L. D. Á.; LIMA, L. D. D.; FERREIRA, M. P.; FuSARO, E. R.; IOZZI, F. L. Desigualdades regionais na saúde: mudanças observadas no Brasil de 2000 a 2016. Ciência \& Saúde Coletiva, v. 22 , n. 4, p. 1055-1064, 2017.

AMARAL FILHO, J. A endogeneização no desenvolvimento econômico regional e local. Planejamento e políticas públicas, n. 23, 2009.

ASHEIM, B. T.; BOSCHMA, R.; COOKE, P. Constructing regional advantage: Platform policies based on related variety and differentiated knowledge bases. Regional studies, v. 45, n. 7, p. 893-904, 2011.

AVELINO, Bruna Camargos; BRESSAN, Valéria Gama Fully; DA CUNHA, Jacqueline Veneroso Alves. Estudo sobre os fatores contábeis que influenciam o Índice Firjan de Desenvolvimento Municipal (IFDM) nas capitais brasileiras. Revista de Educação e Pesquisa em Contabilidade (REPeC), v. 7, n. 3, 2013.

BATISTA JÚNIOR, O. A. B.; SILVA, F. A. G. A função social da exploração mineral no Estado de Minas Gerais. Revista da Faculdade de Direito da UFMG, n. 62, p. 475-506, 2013.

BOGONI, N. M.; HEIN, N.; BEUREN, I. M. Análise da relação entre crescimento econômico e gastos públicos nas maiores cidades da região Sul do Brasil. Revista de Administração Pública, v. 45, n. 1, p. 159-179, 2011.

COSTA, H. K. D. M.; SANTOS, E. M. D. Justiça e sustentabilidade: a destinação dos royalties de petróleo. Estudos Avançados, v. 27, n. 77, p. 143-160, 2013.

DEPARTAMENTO NACIONAL DE PRODUÇÃO MINERAL. RELATÓRIO DIRETORIA DE PROCEDIMENTOS ARRECADATÓRIOS. Arrecadação da CFEM a partir de 2004. 2017. Disponível em: < https://sistemas.dnpm.gov.br/arrecadacao/extra/Relatorios/distribuicao_cfem.aspx>. Acesso em 10 jul. 2017.

DRAIBE, S. M.; RIESCO, M. Estados de bem-estar social e estratégias de desenvolvimento na América Latina: um novo desenvolvimentismo em gestação?. Sociologias, v. 13, n. 27, 2011.

ENRÍQUEZ, M. A. R. D. S. Maldição ou dádiva? Os dilemas do desenvolvimento sustentável a partir de uma base mineira. São Paulo: Signus Editora, 2008.

ENRÍQUEZ, M. A. R. D. S. Mineração e desenvolvimento sustentável-é possível conciliar?. Revista lberoamericana de Economia Ecológica, v. 12, p. 51-66, 2009. 
FINEP, Financiadora de Estudos e Projetos, Apoio e Financiamento, Inova Mineral. 2017. Disponível em: <http://www.finep.gov.br/apoio-e-financiamento-externa/programas-e-linhas/programas-inova/inova-mineral>. Acesso em: 12 set. 2017.

FIRJAN - Federação as Indústrias do Estado do Rio de Janeiro. Relatório. Rio de Janeiro. IFDM. Disponível em: $<$ http://www.firjan.com.br/ifdm/>. Acesso em: 19 fev. 2018.

FIRJAN. Federação as Indústrias do Estado do Rio de Janeiro. Relatório. Rio de Janeiro. IFDM Índice Firjan de Desenvolvimento Municipal. Ano base 2011. Ano 6, 2014.

GADELHA, C. A. G. Saúde e desenvolvimento: uma nova abordagem para uma nova política. Revista de Saúde Pública, v. 46, p. 5-9, 2012.

GALVARRO, M. D. P. S. Q.; BRAGA, M. J.; FONTES, R. M. O. Federalismo fiscal e disparidades no Estado de Minas Gerais. In: ENCONTRO DA ASSOCIAÇÃO NACIONAL DE PÓS-GRADUAÇÃO E PESQUISA EM ADMINISTRAÇÃO, 32., Rio de Janeiro, Anais... Rio de Janeiro, 2008.

GUJARATI, D. N.; PORTER, D. C. Econometria Básica-5. Amgh Editora, 2011.

HARTWICK, J. M. Intergenerational equity and the investing of rents from exhaustible resources. The American Economic Review, v. 67, n. 5, p. 972-974, 1977.

HELLER, L. Relação entre saúde e saneamento na perspectiva do desenvolvimento. Ciência \& Saúde Coletiva, v. 3, p. 73-84, 1998.

HOTELLING, H. The economics of exhaustible resources. Journal of political Economy, v. 39, n. 2, p. 137-175, 1931.

JORGE, M. F.; DANTAS, A. T. Investimento estrangeiro direto, transbordamento e produtividade: um estudo sobre ramos selecionados da indústria no Brasil. Revista Brasileira de Inovação, v. 8, n. 2, p. 481-514, 2009.

KISSLER, L.; HEIDEMANN, F. G. Governança pública: novo modelo regulatório para as relações entre Estado, mercado e sociedade?. Revista de Administração Pública, v. 40, n. 3, p. 479-499, 2006.

LUQUE, C. A.; SILVA, V. M. A lei de responsabilidade na gestão fiscal: combatendo falhas de governo à brasileira. Revista de Economia Política, v. 24, n. 3, p. 404-421, 2004.

MACEDO, M. A. S.; MACHADO, M. A. V.; MACHADO, M. R. Análise da relevância da informação contábil no Brasil num contexto de convergência às normas internacionais de contabilidade. Revista Universo Contábil, v. 9, n. 1, p. 65-85, 2013.

MASSARDI, W. O.; ABRANTES, L. A. Esforço fiscal, dependência do FPM e desenvolvimento socioeconômico: um estudo aplicado aos municípios de Minas Gerais. REGE Revista de Gestão, v. 22, n. 3, p. 295-313, 2015.

MATIAS-PEREIRA, J. A governança corporativa aplicada no setor público brasileiro. Administração Pública e Gestão Social, v. 2, n. 1, p. 109-134, 2010.

MATIAS-PEREIRA, J.; KRUGLIANSKAS, I. Gestão de inovação: a lei de inovação tecnológica como ferramenta de apoio às políticas industrial e tecnológica do Brasil. RAE-eletrônica, v. 4, n. 2, 2005.

MELO, C. A. V.; SOUZA, S. S.; BONFIM, W. L. S. Federalismo e bons governos: uma análise política da gestão fiscal dos municípios. Opinião Pública, v. 21, n. 3, 2015.

OECD - Organisation for Economic Co-operation and Development, Employment Outlook 2017, OECD Publishing, Paris. 2017. Disponível em: <http://www.oecd.org/ newsroom/new-technology-still-under-used-by-businesses.htm>. Acesso em: 12 set. 2017.

PAMPLONA, J. B.; CACCIAMALI, M. C. O paradoxo da abundância: recursos naturais e desenvolvimento na América Latina. Estudos Avançados, v. 31, n. 89, p. 251-270, 2017.

PAULA, F. DE O.; SILVA, J. F. da. O impacto das alianças e do P\&D interno nos desempenhos de inovação e financeiro das firmas. Brazilian Business Review, v. 15, n. 6, p. 533-550, 2018.

PEGG, S. Mining and poverty reduction: Transforming rhetoric into reality. Journal of Cleaner Production, v. 14, n. 3-4, p. 376-387, 2006

POSTALI, F. A. S.; NISHIJIMA, M. Distribuição das rendas do petróleo e indicadores de desenvolvimento municipal no Brasil nos anos 2000S. Estudos Econômicos (São Paulo), v. 41, n. 2, p. 463-485, 2011.

POSTALI, F. A. S.; NISHIJIMA, M. O retorno social dos royalties do petróleo nos municípios brasileiros. In: ENCONTRO DA ASSOCIAÇÃO NACIONAL DOS CENTROS DE PÓS-GRADUAÇÃO EM ECONOMIA, 36., Salvador, Bahia, Anais... Bahia, 2008.

RIBEIRO, E. G.; TEIXEIRA, A.; GUTIERREZ, C. E. C. Impacto dos royalties do petróleo no PIB per capita dos municípios do Estado do Espírito Santo, Brasil. Revista Brasileira de Gestão de Negócios - RBGN, v. 12, n. 34, p. 25-41, 2010.

ROCHA, F.; GIUBERTI, A. C. Composição do gasto público e crescimento econômico: uma avaliação macroeconômica da qualidade dos gastos dos Estados brasileiros. Economia Aplicada, v. 11, n. 4, p. 463-485, 2007.

RODRIGUES, A. C.; MOREIRA, M. A; COLARES, A. C. V. Avaliação da eficiência da aplicação dos royalties da mineração no desenvolvimento social dos municípios mineiros. Revista Ambiente Contábil, v. 8, n. 2, p. 173, 2016.

SILVA, J. M.; CURI, A.; FLORES, J. C. C. A dependência da arrecadação do município de Ouro Preto do setor mineral. Revista Escola de Minas - REM, v. 65, n. 3, 2012. 
SPOHR, G.; FREITAS, C. A. D. Teste da Convergência do PIB Per capita da Agropecuária no Brasil entre 1980 e 2004. Revista de Economia e Sociologia Rural, v. 49, n. 2, p. 341-368, 2011.

TRIDAPALLI, J. P.; BORINELLI, B. B. B.; CAMPOS, M. F. S. D. S.; DE CASTRO, C. Análise dos Gastos Ambientais no Setor Público Brasileiro: Características e Propostas Alternativas. Revista de Gestão Social e Ambiental, v. 5, n. 2, p. 79-95, 2011.

VIANA, M. B.; BURSZTYN, M. A. A. Regularização ambiental de minerações em Minas Gerais. Revista Escola de Minas - REM, v. 63, n. 2, 2010. 